\title{
How Do We Measure Use of Scientific Journals? A Note on Research Methodologies
}

\section{By}

\author{
1. Golnessa GALYANI MOGHADDAM (M.LISc, Ph.D) \\ Assistant Professor, Dept. of Library and Information Science, Shahed University, \\ Tehran, IRAN, e-mail: g_galyani@yahoo.com \\ 2. Mostafa MOBALLEGHI (M.Tech., Ph.D) \\ Razi Metallurgical Research Center (RMRC), Tehran, IRAN \\ e-mail: m_moballeghi@yahoo.com
}

\begin{abstract}
:
Scientific journals represent a significant and growing part of the libraries and many researchers have attempted to measure their use by various methodological approaches till date. In this paper, the author reviews the methodologies employed by researchers working on scientific journals usage. It aims to present an overall picture of the research methods used in the area, in a way that will be of value to anyone seeking to study scientific journals. The author reviews four main research methodologies which are being used for profiling scientific journals usage including questionnaire, interview, citation analysis and transaction log analysis.
\end{abstract}

Keywords: Scientific Journals, Journal Usage, Research Methodology 


\section{Introduction}

Scientific journals are one of the important segments of libraries and one of the most valuable resources in scholarly communication chain. Researchers have been trying to evaluate scientific journals usage through many ways such as using questionnaire, interview and citations count and etc for many years. In spite of developments in information technologies and migration from print to electronic media, there are no fundamental changes in the nature of research methodologies on scientific journals. Of course, advances in technology brought new technical capabilities and new methods such as log file analysis and the Web Impact Factor (WIF) for evaluating journals usage, but the basic principals of research in digital environment are not new. In general, studies of electronic publishing, and metrics for the web, have been widespread in the last decade. A sub-discipline of bibliometrics, called variously 'webometrics' or 'cybermetrics', has emerged (Smith, 2005).

This paper focuses mainly on the methodological approaches adopted by researchers including questionnaire, interview, citation analysis and transaction log analysis. With a view into electronic environment, the author attempts to review the basic principal of research methodology in journal usage studies.

\section{Quantitative and Qualitative Researches}

Before addressing the research methodologies, it is useful to have a look on the issues of quantitative and qualitative researches which are relevant to journals usage studies. Research in general is characterized by the qualitative or quantitative approaches. While quantitative researches focuses on numbers, descriptive statistics, figures and illustrations to show results of the study, the qualitative researches deal with descriptions of concepts and perceptions mainly by interpretations. The results of quantitative studies can be used to make generalizations across the field of research, however, qualitative studies can not be easily generalized.

Quantitative research is often an iterative process whereby evidence is evaluated, theories and hypotheses are refines, technical advances are made and so on. Views regarding the role of measurement in quantitative research are somewhat divergent. Measurement is often regarded as being only a means by which observations are 
expressed numerically in order to investigate casual relations or associations. However, it has been argued that measurement often plays a more important role in quantitative research. In general, quantitative methods are research methods dealing with numbers and anything that is measurable. They are therefore to be distinguished from qualitative methods. Qualitative methods might be used to understand the meaning of the numbers produced by quantitative methods. Using quantitative methods, it is possible to give precise and testable expression to qualitative ideas.

The other difference between quantitative and qualitative researches is the sample of the study. With a view of generalization, the sample of the quantitative studies has to be statistically large enough to represent the whole research population whilst qualitative studies select a small number of subjects and analyse the results by much more details.

Though, quantitative methods are seen to produce objective, value-free knowledge, qualitative methods are seen to yield no more than subjective, value-laden accounts, and this is the other dissimilarity between quantitative and qualitative research. Aligned against each other, the two approaches are reduced to competing research modalities within science fields.

\section{Questionnaire}

Questionnaire is a common method of data gathering in journals usage studies. Some experts believe that "a survey is only as good as the questions it asks" (Zikmund, 2003). While common sense and good grammar are important in question writing, more is required in the art of questionnaire design. To assume that people will understand the questions is a common error. People simple may not know what is being asked and may refuse to answer personal questions too. Good questionnaire design is a key to obtaining good survey results.

Zikmund pointed out in his book that 'relevancy' and 'accuracy' are very important in questionnaire design. A questionnaire is 'relevant' if no unnecessary information is collected and if the information that is needed to solve the research problem is obtained. 'Accuracy' means that the information is reliable and valid. In general, researcher should use simple, understandable, unbiased, unambiguous, nonirritating words but no step-by-step procedure to ensure accuracy in question writing 
can be generalized across various researches. Respondents tend to be more cooperative when the subject of the research is interesting to them. Also, if questions are not lengthy, difficult to answer, or ego-threatening, there is a higher probability of obtaining unbiased answers. Zikmund has given some guidelines in developing a questionnaire in his book which can be useful in designing questionnaire for beginners (for further study see Zikmund, 2003).

Knowing how each question should be phrased requires familiarity with the different types of questions. Open-ended response questions present some problem or question and ask the respondent to answer in his or her own words. Fixed-alternative questions require less interviewer skill, take less time, and are easier to answer. In fixedalternative questions the respondents is given specific limited alternative responses and asked to choose the one closest to his or her own viewpoint. Though standardized responses are easier to code, tabulate, and interpret, care must be taken to formulate the responses not to overlap. Respondents whose answers do not fit any of the fixed alternatives may be forced to select alternatives they really do not mean. Open-ended questions are especially useful in exploratory research or at the beginning of a questionnaire. They make a questionnaire more expensive to analyze because of the uniqueness of the answers. Interviewer bias can also influence the responses to openended questions.

It may be noted here that question sequence can be very important to the success of a survey. The opening questions should be designed to interest respondents and keep them involved. According to Zikmund personal questions should be postponed to the middle or end of the questionnaire. General questions should precede specific ones. In a series of attitude scales, the first response may be used as an anchor for comparison to the other responses. The order of alternative on closed questions can affect the results. Filter questions are useful to avoid unnecessary questions that do not apply to a particular respondent. Finally, an attractive questionnaire encourages a response; a carefully phrased title can also encourage responses.

Once the questionnaire is ready, it should be pre-tested through a pilot survey involving the respondents in the proposed sampling frame. This exercise is mainly intended to test the degree of understanding the meaning of the questions, difficulty in 
understanding the questions by the respondents if the meaning of the questions is conveyed correctly, to check the relevance of the questions and etc. The purpose of pretesting of questionnaire is to obtain information to improve its content, format and sequence. Based on the information, the questionnaire should be revised in its format, content and sequence for final use in the survey.

Questionnaire-based studies have some disadvantages, for example, much time has to be spent in designing and piloting the questionnaire. Analysis of the results, even with the aid of an appropriate computer package, is also time-consuming.

\section{Interview}

Many usage survey data are being obtained when individual responded to questions asked by human interviewers or listed on questionnaires. Interviewers communicated with respondents face-to-face or over the telephone or respondents filled out self-administered paper questionnaires, which were typically distributed by mail. Each interview method has its advantages and disadvantages as well.

In personal/indivitual interview, the face-to-face interaction between interviewer and respondent has several characteristics that help researchers obtain complete and precise information. Zikmund believes that an important characteristic of personal interviews is the opportunity to follow up, by probing. If a respondent's answer is brief or unclear, the researcher may ask for a clearer or more comprehensive explanation. The personal interview is especially useful for obtaining unstructured information. Complex questions that cannot easily be asked in telephone or mail surveys can be handled by skillful interviewers. If the research objective requires an extremely lengthy questionnaire, personal interviews may be the only alternative and it can be much longer than telephone interviews. In addition, the respondent who grows bored with a telephone interview may terminate the interview at his o her discretion simply by hanging up the phone. While some people are reluctant to participate in a survey, the presence of an interviewer generally increases the percentage of people willing to complete the interview. Respondents are generally not required to do any reading or writing - all they have to do is talk. 
In spite of the mentioned advantages, there are some disadvantages for personal interview as well. For example, respondents are not guaranteed anonymity and therefore may be reluctant to provide confidential information to another person. There is some evidence that the demographic characteristics of the interviewer influence respondents' answers. One research study revealed that male interviewers produced larger variance than female interviewers in a survey where 85 percent of the respondents were female. Older interviewers, interviewing older respondents, produced more variance than older age combinations, whereas younger interviewers, interviewing younger respondents, produced the least variance (Frieman and Butler, 1976).

Differential interviewer techniques may be a source of interviewer bias. The rephrasing of a question, the interviewer's tone of voice, and the interviewer's appearance may influence the respondent's answer. The other disadvantage of personal interview is its cost, as it is generally more expensive than mail, Internet, and telephone surveys. The geographic proximity of respondents, the length and complexity of the questionnaire, and the number of people who are nonrespondents because they could not be contacted all influence the cost of the personal interview.

Telephone interview is the other methodology which is being used in usage studies. Advances in computer technology allow responses to telephone interviewers to be entered directly into a computer in a process known as 'computer-assisted telephone interviewing" (CATI). Telephone interviewers are seated at computer terminals. A monitor displays the questionnaire, one question at a time, along with precoded possible responses to each question. The interviewer read each question as it is shown on the screen. When the respondent answers, the interviewer enters the response into the computer, and it is automatically stored in the computer's memory when the computer displays the next question on the screen. A computer-assisted telephone interview requires that answers to questionnaires be highly structured.

The advantages and disadvantages of telephone interviews are different from those of personal interviews. The speed of data collection is a major advantage of telephone interviewing. Whereas data collection with mail or personal interviews can take several weeks, hundreds of telephone interviews can be conducted literally overnight. When the interviewer enters the respondents' answers directly into a 
computerized system, data processing can be done even faster. Telephone interviews are relatively lees expensive. It is estimated that the cost of telephone interviews is less than 25 percent of the cost of face-to-face personal interviews. Travel time and cost are eliminated (Zikmund, 2003). Telephone interviews are more impersonal than face-to-face interviews. Respondents may answer embarrassing or confidential questions more willingly in a telephone interview than in a personal interview.

\section{Citation Counts / Impact Factor}

Citation and article counts are important indicators of how frequently current researchers are using individual journals, however, citation analysis does not represent all of journal usage as authors do not cite all the articles they read and, moreover, not every journal reader is an "author". There are some concerns regarding use of citation as an indicator of use.

One concern is gratuitous citations, which are usually self-citations but may also be the result of referees who insist on having their work cited when they review a manuscript. The bottom line is that although these articles may indeed be cited, they may not actually add value to the articles that cite them. Another concern is "negative" citations, or articles that are cited because of errors or as part of a critique of an existing literature. That is, an article may be cited precisely because it does not advance the state of knowledge or because it takes us down the wrong path (McWilliams, 2005). Kacmar and Whitfield (2000) therefore cautioned that a finer grain analysis is necessary when evaluating the influence of individual articles.

The impact factor is a well-known tool for measuring citation and also one of the famous quantitative tools for ranking, evaluating, categorizing, and comparing journals. The Institute for Scientific Information, or ISI (producers of the Science Citation Index and the Social Sciences Citation Index), has been publishing impact factor since 1975 in its Journal Citation Report (JCR). Journals' impact factor is becoming an increasingly important parameter for evaluating journals all around the world. However, there are some debates regarding the suitability of impact factor for considering quality of journals. 
Korobkin believes that impact factor is an indirect method to evaluate journals value and the methods is not perfect. He pointed out:

"Of the methods for indirectly evaluating a journal's scholarly value, citation frequency analysis promises to create the best incentives for the production of more valuable scholarship. This methodology gives journal editors the incentive to select articles for publication that are most likely to be cited in the future. This methodology is imperfect, as the most cited articles are not necessarily the most valuable ones. The methodology creates an incentive, for example, for journals to publish articles on popular subjects, even if this means accepting pieces of marginally lower quality than available articles on less popular topics. This incentive, however, is substantially mitigated in the context of specialty journals by virtue of the journals' own subject matter limitations" (Korobkin, 1999).

Therefore, impact factor should be used in conjunction with other measures to evaluate the quality, influence and use of a journal.

In addition to impact factor, today there is a new method which is called Web Impact Factor (WIF). Ingwersen (1998) proposed the Web Impact Factor (WIF) as the online equivalent of the ISI Journal Impact Factor. The Journal Impact Factor is based on the citation counts of a journal over a specified period of time, compared with the citable articles published in the journal. In contrast, the Web Impact Factor is based on the number of links made to a web site, compared with the size (usually the number of pages) of the website. The WIF provides quantitative tools for ranking, evaluating, categorizing, and comparing web sites, top-level domains and sub-domains.

This new method also should be used with enough care. Rousseau (2002) argues that care must be exercised when using impact factors, and that a battery of different impact factors should be evaluated. This implies that Web Impact Factors or a similar web based impact factor could be valuable in supplementing evaluation of LIS e-journals. Marek and Valauskas (2002) have also explored the use of web logs, recording hits, to evaluate the use of electronic journal articles, and identify 'classic' articles. 


\section{Transaction Log}

Transaction log files generated by computers do record the pages (topics or content) viewed by users and this is perhaps the most interesting aspect of the logs. Transaction Log Analysis (TLA) provides a useful means of collecting large amounts of quantitative data relating to journals usage. The logs record interactions between end users and web-based search tools, allowing the researcher to study different aspects of each search session, such as the number of keywords entered, and the nature of any modifications to a search query. This is a new methodology in digital environment with the help of technological advances and the Web as well. Many experts have been using $\log$ file analysis to evaluate scholarly network-based journals usage in recent years. The idea behind this method is 'computer records every hit and every search, retrieve, download or etc', therefore analysing the log file may show the usage patterns of users.

Some researchers have highlighted advantages of this method, for example, Nicholas and et al. (2001) suggest that log data are unfiltered and automatically collected and there is no human interference in the process of data collection except in the interpretation. In addition, log data are non-intrusive. They provide the researcher with direct information about what millions of people have done, not what they say they might, or would, do; not what they were prompted to say; and not what they thought they did (Nicholas and Huntington, 2003). Log analysis is also an efficient way to gather longitudinal usage data. There is no time limitation as long as the log files exist and there is no need for sampling in log analysis (Nicholas et al., 2005). In the case of combination of this method with survey and interview studies, log analysis is an effective way to detect discrepancies between what users say they do (for example, in a focus group study) and what they actually do when they use an online system or web site (Covey, 2002). In fact, log analysis is a suitable method for raising evidence-led questions to be asked in questionnaire surveys or interview studies from the users.

In spite having the mentioned advantages, log file analysis has some disadvantages and limitations which are reported in the literature. For example, there are some difficulties in differentiating user performance from system performance (Jamali et al., 2005). In the case of web log analysis, it should be borne in mind that it is computer or computer networks which are the virtual users of the web. Log files of web servers 
record the action of these computers and computer networks and not directly the action of end users (Nicholas et al., 2000). The difficulty in identifying users is another factor that inhibits applying log analysis to studying user behaviour. Kurth (1993) pointed out the possibility that a user may move from terminal to terminal while using a system or two users may alternatively use a single terminal. This is very likely to happen with public terminals, located in libraries. Log analysis, as it is clear from its name, just records the interaction between an information system and a user whose identity usually is not clear. Therefore, transaction log data does not provide us with anything on the users' perception of their searches (Jamali et al., 2005).

\section{Discussion and Conclusion}

Traditional approaches and tools for conducting usage surveys remain popular, though, we should pointed out here that information technology is practically having a profound impact on research. While obtaining quantitative data was time consuming in print journal era, the information technology brought a lot of capabilities in collecting quantitative usage data. Quantitative data are considered as an important tool for performance measurements of libraries for many years. Today, librarians can measure performance of theirs libraries in a better and faster ways. However, there are no fundamental changes in the nature of research methodologies on scientific journals.

In this paper four main methodologies of journals usage studies are addressed. Each method has its own strengths and weaknesses. These methods are being adopted by researchers in accordance with their research objectives, feasibility, convenience and etc. Questionnaire is considered as a popular method in journals usage studies. Interview is a method to obtain more qualitative data, though citation analysis and particularly impact factor is a quantitative method. In spite of some debate over suitability of impact factor for considering quality of journals, citations analysis and JCR' impact factors are becoming popular research tools for usage studies in recent years. There are a large number of research papers which reported citation-based analyses on journals usage all around the world. 
Questionnaire-based, interview-based and citation-based surveys are applied in journals usage studies for many years in a traditional way. Advances in information technology help researchers apply these methods in more effective and easier ways. They may use online questionnaire through the Internet and 'computer-assisted telephone interviewing' to collect data. They may use impact factor by surfing in the Internet as impact factors of ISI-ranked journals are available on the Web. The Internet obviously made the journals usage studies much easier than before. We can make conclusion that while information technology facilitates the traditional research methods, the basic principal of research methodologies are still applicable in electronic environment.

We may noted here information technology brought new research methodology itself which is different from traditional methods. Transaction log analysis is a new methodological approach which is more technical and seems to be borrowed from computer sciences. The other new method is the Web Impact Factor (WIF). These new methods are reported to be used in journals usage particularly electronic journals usage studies. The Web obviously provides a greater range of measures than are available in the print environment. 


\section{References}

COVEY, D.T. (2002), Usability and usability assessment: library practices and concerns, Council on Library and Information Resources, Available at: http://www.clir.org/pubs/reports/ pub105/pub105.pdf (accessed July 11, 2007).

FRIEMAN, J., BUTLER, E. (1976, Spring), Some sources of interviewer variance in surveys, Public Opinion Quarterly: 79-81.

HOEFFEL, C. (1988), Journal impact factors [letter]. Allergy, 53:1225.

INGWERSEN, P. (1998), Web impact factors, Journal of Documentation, 54 (2): 236243.

JAMALI, H.R., NICHOLAS, D., HUNTINGTON, P. (2005), The use and users of scholarly e-journals: a review of log analysis studies, Aslib Proceedings, 57(6): 554-71.

KACMAR, K.M., AND WHITFIELD, J.M. (2000), An additional rating method for journal articles in the field of management. Organizational Research Methods, 3: 392406.

KOROBKIN, R. (1999), Ranking journals: some thoughts on theory and methodology, Florida State University Law Review, 26: 851-876.

KURTH, M. (1993), The limits and limitations of transaction log analysis, Library Hi Tech, 11(2): 98-104.

MAREK, K., VALAUSKAS, E.J. (2002), Web logs as indices of electronic journal use: tools for identifying a 'classic' article. Libri, 52 (4): 220-230. 
McLEAN, N. (1998), The archiving of electronic scholarly information: executive summary, Available at: http://www.unison.nsw.edu.au/ (Accessed January 4, 2007).

McWILLIAMS, A., SIEGEL, D., VAN FLEET, D.D. (2005, April) Scholarly journals as producers of knowledge: theory and empirical evidence based on data envelopment analysis, Organizational Research Methods, 18(2): 185-102.

NiChOlAS, D., HUNTINGTON, P., LIEVESLEY, N. AND WASTI, A. (2000), Evaluating consumer web site logs: a case study of The Times/The Sunday Times web site, Journal of Information Science, 26(6): 399-411.

NICHOLAS, D., HUNTINGTON, P. AND WILLIAMS, P. (2001), Establishing metrics for the evaluation of touch screen kiosks, Journal of Information Science, 27(2): 61-71. NICHOLAS, D. AND HUNTINGTON, P. (2003), Micro-mining and segmented log file analysis: a method for enriching the data yield from internet log files, Journal of Information Science, 29(5): 391-404.

NICHOLAS, D., HUNTINGTON, P. AND WATKINSON, A. (2005), Scholarly journal usage: the results of deep log analysis, Journal of Documentation, 61(2): 246-80.

SMITH, A.G. (2005), Citations and links as a measure of effectiveness of online LIS journals, IFLA Journal, 31(1): 76-84.

ROUSSEAU, R. (2002) Journal evaluation: technical and practical issues, Library Trends, 50: 418-439.

ZIKMUND, W.G. (2003), Business Research Methods, Thomson Learning, Inc., Eastern Press, Bangalore. 